\title{
OUTCOME OF PERCUTANEOUS NEPHROLITHOTOMY WITHOUT JJ STENT IN COMPARISON TO PERCUTANEOUS NEPHROLITHOTOMY WITH JJ STENT
}

\author{
MD. MOSTAFIZUR RAHMAN ${ }^{1}$, MD. SHAFIQUL ALAM CHOWDHURY ${ }^{2}$, UTTAM KARMAKER ${ }^{3}$, NAZIM \\ UDDIN MD. ARIF ${ }^{4}$, MD. TOWHID BELAL ${ }^{5}$, MOHAMMAD NAZMUL HUDA ${ }^{6}$ AND ABU NASER \\ MOHAMMED LUTFUL HASAN ${ }^{7}$, MD. NABID ALAM ${ }^{8}$
}

\begin{abstract}
Objective: This study aims to evaluate the outcomes of PCNL without JJ ureteric stent in comparison to PCNL with JJ ureteric stent.

Patients and Methods: This observational study intended to compare the outcome between PCNL without JJ stent and PCNL with JJ stent of 50 cases of renal stone disease according to the inclusion and exclusion criteria and randomly assigned to Group - $A$ (PCNL without JJ stent) and Group - B (PCNL with JJ stent). This study was conducted in the department of urology, Dhaka Medical College Hospital from July 2014 to June 2016. During postoperative period, both groups were compared with respect to fever, loin pain, dysuria, frequency of micturation, duration of haematuria, continuation of urine leakage, hospital stay, urinoma and hematoma and urinary tract infection.
\end{abstract}

Results: Among the 50 patients, the mean postoperative hospital stay was significantly longer in PCNL with JJ stent (4.48 \pm 2.14 days) than that of PCNL without $\mathrm{JJ}$ stent (2.60 \pm 0.50 days). The continuation of urine leakage at the site of percutaneous tract was also significantly longer in PCNL with JJ stent than in PCNL without JJ stent $(10.8 \pm 3.18$ hours vs $14.14 \pm 3.28$ hours, $P<0.001)$. Assessment of outcome during 3 weeks showed that out of 25 subjects in Group - B, 9 (36\%) loin pain, 8 (32\%) dysuria, $8(32 \%)$ frequency of micturition, $4(16 \%)$ haematuria and another $7(28 \%)$ urinary tract infection. None of the subjects of Group - A reported same type of complications.

Conclusions: Percutaneous Nephrolithotomy without JJ stent (stentless PCNL) is safe, effective and viable option in a selected group of patients - with stone size d"3 $\mathrm{cm}$, normal preoperative renal function, single percutaneous puncture, minimum bleeding, no perforation of the collecting system, no obstruction and complete clearance of stones, $\mathrm{JJ}$ stent may not be required.

Keywords: Percutaneous Nephrolithotomy (PCNL). Kidney, Ureter \& Bladder (KUB), Intravenous Urogram (IVU).

Bangladesh J. Urol. 2019; 22(2): 110-117

1. Assistant Professor (C.C) of Urology, Medical College for Women \& Hospital, uttara, Dhaka;

2. Professor of Urology, Dhaka medical college Hospital, Dhaka;

3. Associate Professor of Urology, Dhaka medical college Hospital, Dhaka;

4. Assistant Professor of Urology, Uttara Adhunik Medical college, Dhaka; 5Resident Surgeon of Urology, Dhaka medical college Hospital, Dhaka;

6. Medical officer of Urology, Dhaka medical college Hospital, Dhaka, Bangladesh;

7. Assistant registrar of Urology, Dhaka medical college Hospital, Dhaka.

8. Medical Officer of Urology, Bangabandhu Sheikh Mujib Medical University.

Correspondense to: Dr. Md. Mostafizur Rahman, Assistant Professor (C.C), Department of Urology, Medical College for Women \& Hospital , Uttara, Dhaka-1230.

\section{Introduction}

Urinary calculi are the third most common affliction of the urinary tract, exceeded only by urinary tract infections and pathologic conditions of the prostate (Stoller, 2013). Renal stone disease typically affects adult men more commonly than adult women and peak incidence is in the fourth to sixth decades of life (Pearle and Lotan, 2012).

The primary goal of surgical stone management is to achieve maximal stone clearance with minimal morbidity to the patient. Continuing advancements in the field of endourology have allowed most patients 


\section{2(2) 2019}

Outcome of Percutaneous Nephrolithotomy without $\mathrm{J} \mathrm{J}^{11}$ stent in comparison to Percutaneous Nephrolithotomy with $\mathrm{JJ}$ stent

with renal stones to be treated in a minimally invasive procedure. (Matlaga and Lingeman, 2012).

Percutaneous nephrolithotomy (PCNL) is currently the preferred first-line treatment and the operation of choice for the management of large, complex renal calculi. Fernstrom and Johansson first reported the technique of creating a percutaneous track specifically to remove a stone in 1976. Subsequent reports have established PCNL as a routinely used technique to treat patients with large or otherwise complex calculi (Matlaga and Lingeman, 2012). Its high success rate, low morbidity and complication rates have meant that this minimally invasive modality has largely replaced the open surgical approach (Sofer et al, 2010).

The standard PCNL procedure consists of percutaneous access to the kidney and the formation of a working tract connecting the flank surface with the intra renal collecting system to allow endoscopic stone disintegration and removal. A temporary nephrostomy tube is usually left in place at the end of the procedure to tamponade of bleeding, allow drainage, and delayed second-look nephroscopy. A double- $\mathrm{J}$ stent is used for internal renal drainage with a favorable outcome in patients with the advantage of decreased postoperative pain, analgesia requirement and hospitalization days.

Technological advancements and refinements have contributed to further lowering the morbidity associated with this procedure. Such refinements include the use of a smaller working sheath and nephroscope (mini $\mathrm{PCNL}$ ), sealing of the percutaneous access tract with hemostatic agents, substituting general anesthesia with regional blocks (ambulatory spinal tubeless PCNL), avoidance of a nephrostomy tube (tubeless PCNL) and avoidance of both nephrostomy tube and JJ stent (totally tubeless) (Yun et al, 2012).

Current percutaneous nephrolithotomy techniques do not require routine ureteral stenting. Exceptions to this practice include extensive perforation of the collecting system, significant stone burden remains with the need for subsequent shock wave lithotripsy (SWL), ureteral obstruction due to edema, concurrent ureteropelvic obstruction, stone fragment migration into the ureter, supracostal access, and persistent urinary fistula after nephrostomy tube removal.

Although ureteral stents play an essential role in PCNL, the potential complications related to their use should not be underestimated. However, stenting is clearly associated with increased morbidity such as Stent
Symptoms like lower urinary tract symptoms (frequency, urgency and dysuria ) and pain (flank or suprapubic), fever, haematuria, stent-related discomfort affecting daily activities; sexual dysfunction; urinary Tract Infection; stent migration; stent encrustation and forgotten Stent. There are also some disadvantages to using an internal ureteral stent in PCNL including the cost, inconvenience, and cystoscopic removal at a later date (Mendez-Probst et al, 2012).

In selective cases, with normal preoperative renal function and when an uncomplicated percutaneous nephrolithotomy can be completed through a single tract, minimum bleeding, no perforation of the collecting system, no obstruction and complete clearance of stones, JJ stent may not be required.

Several surgeons in different part of the world studied on JJ stentless percutaneous surgery. Stentless percutaneous nephrolithotomy was done by Cheng $C$ et al in 2012 and found feasible, safe and effective procedures. Tubeless and stentless percutaneous nephrolithotomy was done by Vikas Gupta et al in 2004 and found good result.

PCNL has been practiced successfully in many centers in Bangladesh since 2000. Most of the urologists have been giving nephrostomy tube and JJ stent after completion of procedures. Recently stentless PCNL are practicing in selective cases.

Multiple comparative studies have been done in other parts of the world to find out the outcome between PCNL with and without JJ stent. Very few studies has been done regarding this question in Bangladesh. The purpose of the study was to evaluate the results of PCNL with and without JJ stent.

\section{Patients and methods}

This observational study was carried out among the patients with renal stone disease attended at the urology department of DMCH, during July 2014 to March 2016. Selection criteria were stone size is d" $3 \mathrm{~cm}$, normal preoperative renal function, single percutaneous puncture, no perforation or tear in pelvicalyceal system during procedure, complete stone clearance confirmed by fluoroscopy and nephroscopy. Some patients were excluded from the study were patient with anatomical anomaly of the kidney and urinary tract, ureteral obstruction, perforation or tear in pelvicalyceal system during procedure, incomplete stone clearance, complicated procedure e.g. excessive bleeding and injury to the adjuscent organ. 
During clinical evaluation history was taken about previous renal surgery, ESWL, bronchial asthma, diabetes mellitus, hypertension and urinary tract infection. General examination and examination of renal region and other part of genitourinary system were performed. All patients were investigated properly. After a decision for PCNL was taken (the potential participants), the whole procedure of present study was explained to each patient and consent was taken. By this way 50 patients were selected as cases. All the odd numbered cases were allocated for Group - A (PCNL without JJ stent) and the even numbered cases were allocated for for Group - B (PCNL with JJ stent). The first case entering into the operation theater was allocated to Group - A (PCNL without JJ stent) and the next patient was allocated to Group - B (PCNL with JJ stent). For any peroperative complication, cases were excluded from the study and the same allocation were replaced by the successive consecutive cases.

All patients received a short-term perioperative antibiotic prophylaxis accordingly. All PCNL done under standard protocol of the operative procedure. Under general anaesthesia, an open ended 6 Fr ureteric catheter passed up to the kidney transurethrally and secured to a Foley catheter, allowing introducing the contrast media to opacify and distending the collecting system. Percutaneous access was created under fluoroscopic guidance using $18 \mathrm{G}$ access needle with sharp obturator into the selected calyx with the $C$ arm. When the needle appeared in the selected calyx, the obturator was removed, and the correct needle position was confirmed by flow of urine. A 0.035 inch floppy tipped $\mathrm{J}$ guide wire was inserted into the needle and either advanced across the UPJ or coiled within the renal pelvis. Access needle was removed and the skin and fascia incised. A second $\mathrm{J}$ tipped guide wire was introduced into the collecting system passed through the pelvis to the bladder after dilating by screw dilator, which act as a safety and other as working guide wire.

The nephrostomy tract was dilated with alken coaxial metallic dilators (Karl Storz, Germany) up to 24Fr and a $26 \mathrm{Fr}$ Amplatz sheath positioned into the renal collecting systems. The stone was disintegrated using pneumatic lithotripsy. Complete clearance was confirmed fluoroscopically and nephroscopically. If all points in the selection criteria were fulfilled, patients were finally assigned to groups A or B. On completion of the procedure the Amplatz sheath was removed in Group $A$ and patients were managed by keeping a nephrostomy tube within the tract without giving $\mathrm{JJ}$ stent. Ureteric catheter was removed after completion of procedure in Group A. In Group B patients, ureteric catheter was removed and a $6 \mathrm{Fr} \mathrm{JJ}$ stent was placed antigradely over a safety guide wire under direct vision and fluoroscopic guidance. Removal of the Amplatz sheath and putting a nephrostomy tube within the tract, anchored with a deep mattress suture using $2 / 0$ silk and compressed dressing was applied.

Hence 25 patients were treated PCNL without JJ stent in group $A$ and rest 25 patients were treated PCNL with JJ stent in group $B$. The nephrostomy tube was removed when the urine was clear. The JJ stent was removed after 3 weeks.

Postoperative period: During postoperative period, both groups were compared with respect to fever, analgesic requirements, haematuria, urinary leakage, formation of haematoma or urinoma and hospital stay. After completion of procedure- Inj. Pethedine was given in every cases and further analgesic introduced as per demand. In post operative period routinely recorded the temperature, temperature more than $100^{\circ} \mathrm{C}$ for 24 hours categorized as fever. During procedure and after completion of procedure by seeing the urine color assessed the haematuria.

Urine leakage was estimated after removal of nephrostomy tube. Urine leakage was estimated by change of dressing every 4 hours and duration of urine leak was determined after the wound and the overlying dressing was completely dry for 4 hours. Just before discharge the patient were assessed for any haematoma or urinoma at puncture side. At the time of discharge patients were advised to come after 3 weeks for follow up and JJ stent removal. Data on patient's age, size of stone, operating time, postoperative hospital stay and postoperative complications were recorded and compared between the two groups. The result presented in tables, figures, and diagrams.

\section{Results and observations:}

The Present study intended to compare the outcome between Percutaneous Nephrolithotomy without JJ stent and Percutaneous nephrolithotomy with JJ stent of 50 cases of renal stone disease according to the inclusion and exclusion criteria and randomly assigned to Group - A (PCNL without JJ stent) and Group - B (PCNL with JJ stent). The outcome variables were fever, loin pain, dysuria, frequency of micturation, duration of haematuria, continuation of urine leakage, hospital stay, urinoma and hematoma and urinary tract infection. The findings derived from data analysis are presented below. 
Outcome of Percutaneous Nephrolithotomy without $\mathrm{J}\}^{13}$ stent in comparison to Percutaneous Nephrolithotomy with $\mathrm{JJ}$ stent

\section{Age distribution:}

Majority (around $56 \%$ ) of the patients in both the groups were in the age range 30 - 50 years. The groups were not statistically different in terms of age $(p=0.638)$ (Table-I).

Table I

Distribution of patients according to age in groups

\begin{tabular}{lccl}
\hline Age & \multicolumn{2}{c}{ Group } & p value \\
& $\begin{array}{c}\text { Group A } \\
\text { (PCNL without } \\
\text { JJ stent) } \\
(\mathrm{n}=25)\end{array}$ & $\begin{array}{c}\text { Group B } \\
\text { (PCNL with } \\
\text { JJ stent) } \\
(\mathrm{n}=25)\end{array}$ & \\
\hline$\leq 30$ & $2(8.0)$ & $3(12.0)$ & \\
$31-40$ & $8(32.0)$ & $8(32.0)$ & \\
$41-50$ & $8(32.0)$ & $4(16.0)$ & \\
$51-60$ & $5(20.0)$ & $8(32.0)$ & \\
$>60$ & $2(8.0)$ & $3(12.0)$ & \\
Total & $25(100.0)$ & $25(100.0)$ & \\
Mean \pm SD 44.28 \pm 10.28 & $45.76 \pm 11.78$ & 0.638 \\
\hline
\end{tabular}

Values in the parentheses denote corresponding percentage.

Data were analyzed using Student's t-Test and level of significance was $<0.05$.

\section{Size of stone:}

Majority of the patients in both the groups $(76 \%$ in Group-A and 64\% in Group-B) had stone size between $2-3 \mathrm{~cm}$. No significant difference was observed between groups in terms of stone size $(2.22 \pm 0.570$ $\mathrm{cm}$ vs. $2.10 \pm 0.57 \mathrm{~cm}, \mathrm{p}=0.465$ ) (Table II).

Table II

Distribution of patients according to Size of stone between the groups

\begin{tabular}{lccc}
\hline $\begin{array}{l}\text { Size of } \\
\text { stone }(\mathrm{cm})\end{array}$ & $\begin{array}{c}\text { Group A } \\
\text { (PCNL without } \\
\text { JJ stent) } \\
(\mathrm{n}=25)\end{array}$ & $\begin{array}{c}\text { Group } \\
\text { (PCNL with } \\
\text { JJ stent) } \\
(\mathrm{n}=25)\end{array}$ & $\begin{array}{c}\mathrm{p} \\
\text { value }\end{array}$ \\
\hline$<2$ & $6(24.0)$ & $9(36.0)$ & \\
$2-3$ & $19(76.0)$ & $16(64.0)$ & \\
Total & $25(100.0)$ & $25(100.0)$ & \\
Mean \pm SD $2.22 \pm 0.570$ & $2.10 \pm 0.57$ & 0.465 \\
\hline
\end{tabular}

Values in the parentheses denote corresponding percentage.

Data were analyzed using Student's t-Test and level of significance was $<0.05$.

\section{Fever following operation:}

Comparison of fever between the groups shows that $12 \%$ in Group-A and 16\% in Group-B developed fever.

Table III

Comparison of fever following operation between the groups

\begin{tabular}{lccc}
\hline Fever & \multicolumn{2}{c}{ Group } & p \\
& $\begin{array}{c}\text { Group A } \\
\text { (PCNL without }\end{array}$ & $\begin{array}{c}\text { Group B } \\
\text { (PCNL with }\end{array}$ & value \\
& JJ stent) & JJ stent) & \\
& $(\mathrm{n}=25)$ & $(\mathrm{n}=25)$ & \\
\hline Yes & $3(12.0)$ & $4(16.0)$ & 0.684 \\
No & $22(88.0)$ & $21(84.0)$ & \\
\hline Total & $25(100.0)$ & $25(100.0)$ & \\
\hline
\end{tabular}

Values in the parentheses denote corresponding percentage.

Data were analyzed using Chi-square test and level of significance was $<0.05$.

\section{Haematuria:}

Continuation of haematuria shows that $56 \%$ subjects of Group-A and $48 \%$ subjects of Group-B continued haematuria for d" 4 hours, where as $44 \%$ subjects of Group-A and $52 \%$ subjects of Group-B continued haematuria for $>4$ hours with no significant difference between groups (Table-IV).

Table IV

Comparison of continuation of haematuria between the groups

\begin{tabular}{lccc}
\hline $\begin{array}{l}\text { Duration of } \\
\text { haematuria } \\
\text { (hour) }\end{array}$ & $\begin{array}{c}\text { Group A } \\
\text { (PCNL without } \\
\text { JJ stent) } \\
\end{array}$ & $\begin{array}{c}\text { Group B } \\
(\mathrm{PCNL} \text { with }\end{array}$ & $\begin{array}{c}\mathrm{p} \\
\text { JJ stent })\end{array}$ \\
\hline$\leq 4$ & $14(56.0)$ & $(\mathrm{n}=25)$ & \\
$>4$ & $11(44.0)$ & $12(48.0)$ & \\
Total & $25(100.0)$ & $25(100.0)$ & \\
Mean \pm SD & $4.32 \pm 1.77$ & $5.04 \pm 1.81$ & 0.162 \\
\hline
\end{tabular}

Values in the parentheses denote corresponding percentage. Data were analyzed using Chi-square test and level of significance was $<0.05$. 


\section{Urine leakage:}

$84 \%$ of Group-B continued urine leakage for $>12$ hours following operation, where as only $20 \%$ of Group-A continued leakage for the same duration of time. The difference between the groups in terms of continuation of urine leakage $10.8 \pm 3.18$ hours vs $14.14 \pm 3.28$ hours, $\mathrm{P}<0.001$ (Table-V).

\section{Table V}

Comparison of continuation of urine leakage between the groups

\begin{tabular}{|c|c|c|c|}
\hline \multirow{2}{*}{$\begin{array}{l}\text { Duration of urine } \\
\text { leakage (hour) }\end{array}$} & \multicolumn{2}{|c|}{ Group } & \multirow{2}{*}{$\begin{array}{c}\mathrm{p} \\
\text { value }\end{array}$} \\
\hline & $\begin{array}{l}\text { Group A } \\
\text { (PCNL without } \\
\text { JJ stent) } \\
(n=25)\end{array}$ & $\begin{array}{l}\text { Group B } \\
\text { (PCNL with } \\
\text { JJ stent) } \\
(\mathrm{n}=25)\end{array}$ & \\
\hline$\overline{\leq 12}$ & $20(80.0)$ & $4(16.0)$ & \\
\hline$>12$ & $5(20.0)$ & $21(84.0)$ & \\
\hline$\overline{\text { Total }}$ & $25(100.0)$ & $25(100.0)$ & \\
\hline Mean \pm SD & $10.8 \pm 3.18$ & $14.14 \pm 3.28$ & $<0.001$ \\
\hline
\end{tabular}

Values in the parentheses denote corresponding percentage.

Data were analyzed using Chi-square test and level of significance was $<0.05$.

\section{Postoparative hospital stay:}

Comparison of hospital stay between groups demonstrates that over $60 \%$ of the subjects of Group $B$ had stay at hospital for more than 3 days following operation. In Group - A none had to stay at hospital for $>3$ days $($ Table-VI).

Table VI

Comparison of postoperative hospital stay between groups

\begin{tabular}{lccc}
\hline $\begin{array}{l}\text { Postoperative } \\
\text { hospital stay } \\
\text { (Days) }\end{array}$ & $\begin{array}{c}\text { Group A } \\
\text { (PCNL without } \\
\text { JJ stent) } \\
(\mathrm{n}=25)\end{array}$ & $\begin{array}{c}\text { Group B } \\
\text { (PCNL with } \\
\text { JJ stent) }\end{array}$ & $\begin{array}{c}\text { value } \\
(\mathrm{n}=25)\end{array}$ \\
\hline$\leq 3$ & $25(100.0)$ & $10(40.0)$ & \\
$>3$ & $0(0.0)$ & $15(60.0)$ & \\
Total & $25(100.0)$ & $25(100.0)$ & \\
Mean \pm SD & $2.60 \pm 0.50$ & $4.48 \pm 2.14$ & $<0.001$ \\
\hline
\end{tabular}

Values in the parentheses denote corresponding percentage. Data were analyzed using Student's t-Test and level of significance was $<0.05$.
Loin pain, Dysuria, Frequency of micturation and Urinary tract infection:

Assessment of Loin pain, dysuria, frequency of micturation and urinary tract infection during 3 weeks follow up showed that out of 25 subjects in Group - B, $9(36 \%)$ loin pain, $8(32 \%)$ dysuria, 8 (32\%) frequency of micturition and another 7 (28\%) urinary tract infection. None of the subjects of Group - A reported same type of complications (Table VII).

\section{Table VII}

Comparison of loin pain, dysuria, frequency of micturation and urinary tract infection during 3 weeks follow up $(n=50)$

\begin{tabular}{lccc}
\hline $\begin{array}{l}\text { Outcome at } \\
\text { follow up }\end{array}$ & $\begin{array}{c}\text { Group A } \\
\text { (PCNL without } \\
\text { JJ stent) } \\
(\mathrm{n}=25)\end{array}$ & $\begin{array}{c}\text { Group B } \\
\text { (PCNL with } \\
\text { JJ stent) } \\
(\mathrm{n}=25)\end{array}$ & p value \\
\hline Loin pain & $0(0.0)$ & $9(36.0)$ & 0.002 \\
$\begin{array}{l}\text { Dysuria } \\
\text { Frequency of }\end{array}$ & $0(0.0)$ & $8(32.0)$ & 0.004 \\
micturation & $0(0.0)$ & $8(32.0)$ & 0.004 \\
$\begin{array}{l}\text { Urinary tract } \\
\text { infection }\end{array}$ & $0(0.0)$ & $7(28.0)$ & 0.010 \\
\hline
\end{tabular}

Total will not correspond to $100 \%$, because of multiple responses.

Fisher's exact test was done to measure the level of significance.

\section{Discussion}

Since the introduction of PCNL in 1976 for the management of renal stones, it has been evolving and improving in technology and surgical techniques. In standard PCNL, a temporary nephrostomy tube is usually left in place at the end of the procedure to tamponade of bleeding, allow drainage and delayed second-look nephroscopy, and a double- $\mathrm{J}$ stent is used for internal renal drainage. Although ureteral stents play an essential role in PCNL, the potential complications related to their use should not be underestimated. There are inherent problems related to the placement of a JJ stent in terms of urinary tract symptoms that could be severe in some patients. It also requires an office cystoscopy for its removal, adding to the cost of the treatment and a hospital visit ( Mandhani et al, 2003). Currently in selective cases, with normal preoperative renal function and when an uncomplicated 


\section{2(2) 2019}

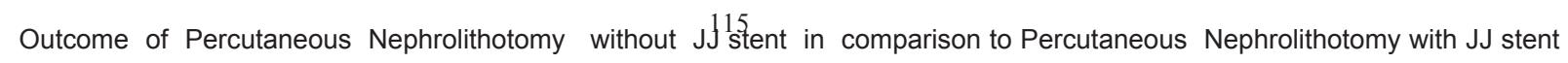

percutaneous nephrolithotomy, JJ stent may not be indicated.

The present study has been designed to compare the outcome of PCNL with and without JJ stent for the management of renal stone disease. Patients with renal calculi undergone PCNL were divided into 2 groups. Patients belong to Group-A were managed by PCNL without JJ stent and patients belong to Group-B were managed by PCNL with JJ stent.

Results of treatment of both groups were compiled and compared. Age, size of the stone and operating time were compared between groups. Postoperative fever, duration of haematuria, urine leakage through percutaneous tract, postoperative hospital stay, Loin pain, Dysuria, Frequency of micturation and Urinary tract infection were compared as outcome variables between groups.

Age ranges of the patients in the present study were between 25 years and 62 years. Majority of the patients in both the groups were in the age range 30 - 60 years. The age range of the present study more or less comparable with the study done by Bellman G.C. et al in 1997 to evaluate the role of routine placement of nephrostomy tube following percutaneous surgery on 50 patients. Study done by Aghamir S.M.K. et al 2004 and Vikas Gupta et al 2004 on tubeless and stentless PCNL where the age range more or less comparable with the present study.

Stone size was another baseline variable. In this study, stone size d" $3 \mathrm{~cm}$ were included and the stone size was calculated radiologically in centimeter. The mean stone size in Group A was $2.22 \pm 0.570 \mathrm{~cm}$ and $2.10 \pm$ $0.57 \mathrm{~cm}$ in Group B. The stone size of both groups was compared and no significant difference was found $(p=0.465)$. Crook et al performed a randomized controlled trial of nephrostomy placement versus tubeless percutaneous nephrolithotomy in 2008 where the mean stone size was $2.16 \mathrm{~cm}$ vs $1.75 \mathrm{~cm}$. This is nearly similar to the present study.

After completion of the procedure, the patients were evaluated by fever, duration of macroscopic haematuria, urinary leakage through percutaneous tract, haematoma, urinoma, hospital stay and assessment of outcome during 3 weeks.

Three patients of PCNL without JJ stent and four patients of PCNL with $\mathrm{JJ}$ stent had fever, which was not significant. Fever was associated with urinary tract infection which resolved quickly after changing antibiotic.

The duration of macroscopic haematuria in both groups were compared. In present study haematuria in Group A was 4.32 \pm 1.77 hours and Group B was $5.04 \pm 1.81$ hours. No significant difference observed between the groups. None of the patients in both groups required postoperative blood transfusion. In a study done by Desai et al in 2004 where the mean duration of haematuria were $2.5 \pm 0.5$ hours in patients of PCNL with large bore nephrostomy tube and $2.7 \pm 0.5$ hours in tubeless group. No significant differences in occurrence of haematuria were observed in that study.

In the present study mean percutaneous tract side urine leak was $10.8 \pm 3.18$ hours in stentless group and $14.14 \pm 3.28$ hours in PCNL with JJ stent group, which was statistically significant. The stentless group was associated with the shortest duration of postoperative percutaneous tract site urine leak. In this study patients were managed by keeping a nephrostomy tube within the tract in both Group A and Group B patients. The nephrostomy tube was removed when the urine was clear. Urine leakage was estimated after removal of nephrostomy tube. Urine leakage was estimated by change of dressing every 4 hours and duration of urine leak was determined after the wound and the overlying dressing was completely dry for 4 hours. Desai M.R. et al studied that tubeless PCNL had the shortest duration (4.8 hours) of percutaneous tract site urine leak compared to PCNL with nephrostomy tube 21.4 hours, $p<0.05$. Although urine leak usually resolve spontaneously, its leak from the percutaneous tract site can often be bothersome to the patients.

Patients undergone the JJ stentless PCNL had lower postoperative hospital stay to compare with PCNL with JJ stent. In this study postoperative hospital stay was $2.60 \pm 0.50$ days for the patient of PCNL without $\mathrm{JJ}$ stent and $4.48 \pm 2.14$ days for PCNL with JJ stent. The study of B.Lojanapiwat et al 2001 and Aghamir et al 2004 Gupta V et al 2004 on nephrostomy tubeless and JJ stentless percutaneous nephrostomy compared with percutaneous nephrolithotomy with nephrostomy tube with JJ stent. They found significant shorter hospital stay for PCNL without nephrostomy tube and JJ stent.

In the present study assessment of outcome during 3 weeks showed that out of 25 subjects in Group - B, 9 (36\%) loin pain, $8(32 \%)$ dysuria, 8 (32\%) frequency of micturition and another 7 (28\%) urinary tract infection. None of the subjects of Group - A reported same type of complications. The stent related complications 
among the Group - B patients were managed by analgesics, antispasmodics, anticholinergics and antibiotics in majority cases but one required early stent removal for severe dysuria not responding to conservatives and two required early stent removal for haematuria.

Joshi et al 2014 conducted a prospective study among the patients undergoing percutaneous nephrolithotomy (PCNL) with Double-J stent placement in comparison to PCNL with externalized ureteral catheter placement. A total of 16 stent related complications were seen in PCNL with Double-J stent placement, among them six $(24 \%)$ patients had fever due to stent, five $(20 \%)$ had dysuria with two requiring early stent removal for grade IIIA dysuria; five (20\%) had haematuria with two requiring early removal due to grade IIIA haematuria. In patient with PCNL with externalized ureteral catheter placement, only seven patients experienced postoperative complications and among them six had grade I and II fever which was managed conservatively, one patient had dysuria and haematuria grade III A and had his Foley's catheter and ureteric catheter removed on second day. The modification in standard PCNL in their study has the potential advantages of reduced stent-related morbidity, significant reduction in the cost, stent-related discomforts and the need for postoperative cystoscopy to remove the double-J stent can be avoided. This findings correlated with the present study.

In a study by Mandhani et al prospectively evaluated the outcome of tubeless percutaneous nephrolithotomy with or without Double-J stent. They showed 3 patients had severe stent related problems in the form of extreme frequency of urine and flank pain during voiding. One patient required stent removal on day 4 as urinary frequency, dysuria and loin pain while voiding did not respond to medication. The other 2 cases could be managed with oral anticholinergic. They concluded that avoiding use of the Double-J stent may not compromise the safety of tubeless percutaneous nephrolithotomy. This findings is nearly similar to the present study.

Moosanejad et al compared the totally tubeless percutaneous nephrolithotomy and standard percutaneous nephrolithotomy techniques. Complications were observed in 6 patients in the standard PCNL group (15\%) (prolonged urine drainage in 4 , fever in 1 and hematuria in 1 patients) and in 4 patients in the totally tubeless PCNL group (10\%) (long- lasting renal colic in 2 and fever in 2 patients). Their results showed that PCNL without stent is a safe and effective technique and can be suggested for patients with staghorn stones. This technique was associated with decreased pain, analgesic need, operation time, and hospitalization time. They believe that a normal peristaltic ureter is the best drainage tube.

\section{Conclusion}

Percutaneous Nephrolithotomy without JJ stent (stentless PCNL) is safe, effective and viable option in a selected group of patients - with stone size d" $3 \mathrm{~cm}$, normal preoperative renal function, single percutaneous puncture, minimum bleeding, no perforation of the collecting system, no obstruction and complete clearance of stones, JJ stent may not be required. Comparing the findings of the present study, it can be concluded that JJ stentless PCNL may not compromise the safety of standard PCNL and the postoperative outcome of PCNL without JJ stent is better than PCNL with $\mathrm{JJ}$ stent in uncomplicated cases.

\section{References Cited}

1. Aghamir, SM, Hosseini, SR, Gooran, S 2004, 'Totally tubeless percutaneous nephrolithotomy', J Endourol, vol. 18, pp. 647-648.

2. Anderson, JK, \& Cadeddu, JA 2012, 'Surgical Anatomy of the Retroperitoneum, Adrenals, Kidneys, and Ureters,' In Wein, AJ, Kavoussi, LR, Novick, AC, Partin ,AW, Peters, CA (eds), Campbell-Walsh Urology, Philadelphia: Elsevier Saunders, pp. 4-32.

3. Bellman, GC, Davidoff, R, Candela, J, Gerspach, J, Kurtz S, Stout L 1997, 'Tubeless percutaneous renal surgery', J Urol, vol. 157 (5), pp. 1578-82.

4. Cheng, C, Jianhua, Z, Runyun, G, Jiang, L, Jiarun, S, Hui Z, Xiaodong, L, Jihong, S 2012, 'Stentless percutaneous nephrolithotomy for upper urinary tract calculus: a preliminary report of 13 cases', Journal of Clinical Urology, pp. 12.

5. Crook, TJ, Lockyer, CR, Keoghane, SR, and .Walmsley, BH 2008, 'A Randomized Controlled Trial of Nephrostomy Placement Versus Tubeless Percutaneous Nephrolithotomy', The Journal of Urology, vol. 180, pp. 612-614.

6. Desai, MR, Kukreja, RA, Desai, MM, Mhaskar, SS, Wani, KA, Patel, SH, Bapat, SD 2004, ' A prospective randomized comparison of type of nephrostomy drainage following percutaneous 


\section{2(2) 2019}

Outcome of Percutaneous Nephrolithotomy without $\mathrm{J} \mathrm{J}^{117}$ stent in comparison to Percutaneous Nephrolithotomy with $\mathrm{JJ}$ stent

nephrostolithotomy: large bore versus small bore versus tubeless', The Journal of Urology, vol. 172, pp. 565-567.

7. Gupta V, Sadasukhi, TC, Sharma, KK, Yadav, RG and Mathur R 2005, 'Tubeless and stentless percutaneous nephrolithotomy', BJU International, vol. 95, pp. 905-906.

8. Joshi, R, Sharma, A, Dongol, UM, Singh, DR 2014, ' Double J stenting compared with ureteral catheterization in Percutaneous Nephrolithotomy', Journal of Kathmandu Medical College, vol. 3 (2), pp. $63-67$.

9. Lojanapinat, B, Soonthoruphan, S, Wudhikarns, S 2001, 'Tubeless percutaneous nephrolithomy in selected patients', J Endourol, vol. 15, pp. 711-713.

10. Matlaga, BR, Lingeman, JE 2012, 'Surgical management of upper urinary tract calculi', In Wein AJ, Kavoussi LR, Novick AC, Partin AW, Peters CA (eds), Campbell-Walsh Urology, 10 ${ }^{\text {th }}$ edn, Philadelphia: Elsevier Saunders, pp. 13581410.

11. Mendez-Probst, CE, Razvi, H, Denstedt, JD 2012, 'Fundamentals of Instrumentation and Urinary Tract Drainage', In Wein, AJ, Kavoussi, LR, Novick, AC, Partin, AW, Peters, CA (eds), Campbell-Walsh Urology, $10^{\text {th }}$ edn, Philadelphia: Elsevier Saunders, pp. 177-191.

12. Mandhani, A, Goyal, R, Vijjan, V, Dubey, D and Kapoor, R 2007, ' Tubeless Percutaneous Nephrolithotomy - Should a Stent be an Integral Part?', The Journal of Urology, vol. 178, pp. 921924.

13. Mandhani, M, Rakesh, K, Wahid, Z, Anant, K, Bhandari, M and Gambhir, S 2003, ' Is 2 week duration sufficient for stenting in endopyelotomy? ', J Urol, vol. 169, pp. 886.

14. Moosanejad, N, Firouzian, A, Hashemi, SA, Bahari, M and Fazli, M 2016, 'Comparison of totally tubeless percutaneous nephrolithotomy and standard percutaneous nephrolithotomy for kidney stones: a randomized, clinical trial', Brazilian Journal of Medical and Biological Research, vol. 49(4), pp. 1-6.

15. Pearle MS, Lotan $Y$ 2012, 'Urinary Lithiasis: Etiology, Epidemiology and Pathogenesis', In Wein, AJ, Kavoussi, LR, Novick, AC, Partin, AW, Peters, CA (eds), Campbell-Walsh Urology, 10 ${ }^{\text {th }}$ edn, Philadelphia: Elsevier Saunders, pp. 12581287.

16. Rassweiler, JJ, Renner, C, Eisenberger, F 2000, 'The management of complex renal stones', BJU International, vol. 86, pp. 919-928.

17. Stoller, ML 2013, 'Urinary Stone Disease', In McAninch, JW, Lue, TF (eds), Smith \& Tanagho's General Urology, $18^{\text {th }}$ edn, McGraw-Hill, pp. 249272.

18. Sofer, M, Lidawi, G, Keren-Paz, G, Yehiely, R, Beri, A and Matzkin, H 2010, ' Tubeless percutaneous nephrolithotomy: first 200 cases in Israel', Isr Med Assoc J, vol. 12, pp. $164-167$.

19. Wickham, JE, Miller, RA, Kellett, MJ, Payne, SR 1984, 'Percutaneous nephrostolithotomy: One stage or two?', Br J Urol, vol. 56, pp. 582 - 585.

20. Winfield, HN, Weyman, P, Clayman, RV 1986, 'Percutaneous nephrostolithotomy: Complications of premature nephrostomy tube removal', J Urol, vol. 136, pp. 77 - 79.

21. Wolf JS 2012, 'Percutaneous Approaches to the Upper Urinary Tract Collecting System', In Wein, AJ, Kavoussi, LR, Novick, AC, Partin, AW, Peters, CA (eds), Campbell-Walsh Urology, 10 ${ }^{\text {th }}$ edn, Philadelphia: Elsevier Saunders, pp. 1325-1356.

22. Yun, SI, Lee, YH, Kim, JS, Cho, SR, Kim, BS, Kwon, JB 2012, 'Comparative study between Standard and Totally tubeless percutaneous nephrolithotomy', Korean J Urol, vol. 53, pp. 785789. 